Check for updates

Cite this: Nanoscale Adv., 2019, 1, 4415

\title{
Ultrafine PdAu nanoparticles immobilized on amine functionalized carbon black toward fast dehydrogenation of formic acid at room temperature $\uparrow$
}

\author{
Luming Wu, ${ }^{a}$ Baoxia Ni, ${ }^{a}$ Rui Chen, ${ }^{a}$ Chengxiang Shi, ${ }^{a}$ Pingchuan Sun (D) bc \\ and Tiehong Chen (D) *ac
}

\begin{abstract}
Ultrafine and highly dispersed PdAu nanoparticles were immobilized on amine functionalized carbon black (VXC-72- $\mathrm{NH}_{2}$ ) for dehydrogenation of formic acid (FA). The introduction of amines is of vital importance for the formation of ultrafine PdAu nanoparticles $(\sim 1.5 \mathrm{~nm})$. Moreover, the presence of the amino groups also increased the electron density of PdAu nanoparticles, and this effect facilitated the formation of metalformate, which further enhanced the rate of the catalytic dehydrogenation of FA. The as-prepared $\mathrm{Pd}_{0.6} \mathrm{Au}_{0.4} / \mathrm{VXC}-72-\mathrm{NH}_{2}$ exhibited high catalytic activity and $100 \% \mathrm{H}_{2}$ selectivity for dehydrogenation of formic acid without any additive, with turnover frequency (TOF) values of $7385 \mathrm{~h}^{-1}$ at $298 \mathrm{~K}$ and 17724 $\mathrm{h}^{-1}$ at $333 \mathrm{~K}$, which are the highest TOF values ever reported among heterogeneous catalysts for FA dehydrogenation.
\end{abstract}

Received 30th July 2019

Accepted 22nd September 2019

DOI: 10.1039/c9na00462a

rsc.li/nanoscale-advances

could bring about basic coordination sites to facilitate the anchoring of well-dispersed and ultrafine NPs for high activity. ${ }^{8-10}$ However, in most cases, the procedures presently used for the synthesis of $N$-functionalized carbon involve high temperature or long pyrolysis time, which would greatly hinder their practical applications. ${ }^{11,12}$ Hence, controllable surface modification of carbon materials by facile and low temperature methods to support metal NPs with high dispersion remains a critical challenge.

Hydrogen is a sustainable and clean energy carrier for the establishment of a fuel-cell-based hydrogen economy. ${ }^{13}$ Formic acid (FA, $\mathrm{HCOOH}$ ) has emerged as one of the most promising hydrogen storage compounds due to its high hydrogen density (4.4 wt\%), nontoxicity and excellent stability. ${ }^{14-17}$ Hydrogen stored in FA can be released via the dehydrogenation pathway $\left(\mathrm{HCOOH} \rightarrow \mathrm{CO}_{2}+\mathrm{H}_{2}\right.$ ) and the dehydration pathway $(\mathrm{HCOOH}$ $\left.\rightarrow \mathrm{CO}+\mathrm{H}_{2} \mathrm{O}\right){ }^{18,19}$ The dehydration pathway is an undesired side reaction and should be strictly controlled because $\mathrm{CO}$ is highly toxic and capable of poisoning Pt-based fuel cell catalysts. In recent years, many heterogeneous catalysts have been developed for FA dehydrogenation, ${ }^{20-37}$ and among them amine functionalized graphene, MOFs and mesoporous silica are generally used to support gold $(\mathrm{Au})$, palladium $(\mathrm{Pd})$ and $\mathrm{Pd}-$

${ }^{a}$ Institute of New Catalytic Materials Science, School of Materials Science and Engineering, Key Laboratory of Advanced Energy Materials Chemistry (MOE), Nankai University, Tianjin 300350, PR China. E-mail: chenth@nankai.edu.cn

${ }^{b}$ Key Laboratory of Functional Polymer Materials of Ministry of Education, College of Chemistry, Nankai University, Tianjin 300071, PR China

${ }^{c}$ Collaborative Innovation Center of Chemical Science and Engineering (Tianjin), Tianjin 300071, PR China

$\dagger$ Electronic supplementary information (ESI) available. See DOI: based alloy NPs. Depending on the nature of support materials and preparation methods, some catalysts exhibited efficient dehydrogenation activities. For instance, Jiang and coworkers prepared AuPd NPs supported on amine functionalized graphene, and the catalyst gave a TOF value of $4445.6 \mathrm{~h}^{-1}$ at 298 $10.1039 / \mathrm{c} 9$ na00462a 
carbon functionalized with $p$-phenylenediamine, which exhibited a high TOF of $5638 \mathrm{~h}^{-1}$ at $348 \mathrm{~K} .^{25} \mathrm{Xu}$ and coworkers prepared highly dispersed palladium nanoclusters immobilized on a nitrogen (N)-functionalized porous carbon support with a TOF of $8414 \mathrm{~h}^{-1}$ at $333 \mathrm{~K}^{10}$

Compared with graphene, MOFs, mesoporous silica, mesoporous carbon, active carbons and carbon black are industrialscale produced and cost-effective supports, which have widely been used as the support of noble metals for many industrial catalysts. Herein, we report a facile and efficient approach to synthesize well-dispersed PdAu NPs immobilized on amine functionalized carbon black (VXC-72). The introduction of amines is of vital importance for the synthesis of ultrafine PdAu nanoparticles $(\sim 1.5 \mathrm{~nm})$, and the as-prepared $\mathrm{Pd}_{0.6} \mathrm{Au}_{0.4} / \mathrm{VXC}-$ 72- $\mathrm{NH}_{2}$ exhibited high catalytic activity and $100 \% \mathrm{H}_{2}$ selectivity for dehydrogenation of formic acid without any additive, with TOF values of $7385 \mathrm{~h}^{-1}$ at $298 \mathrm{~K}$ and $17724 \mathrm{~h}^{-1}$ at $333 \mathrm{~K}$, which are the highest TOF values ever reported among heterogeneous catalysts for FA dehydrogenation. This work may provide a general and applicable approach to improve the properties of carbon supported noble metal catalysts, which are widely employed in industrial applications such as hydrogenation, oxidation and electrocatalysis.

\section{Experimental}

\subsection{Chemicals and materials}

All the reagents were of analytical purity and used as received without further purification. VXC-72 was purchased from Ailian Electronic Technology Co., Ltd, Tianjin. Tetrachloroauric (III) acid was purchased from Shanghai Macklin Biochemical Co., Ltd. Sodium tetrachloropalladate, 3-aminopropyltriethoxysilane (APTES), formic acid (FA), and sodium borohydride $\left(\mathrm{NaBH}_{4}\right)$ were purchased from Aladdin (China). Nitric acid $\left(\mathrm{HNO}_{3}\right)$ and ethanol $\left(\mathrm{CH}_{3} \mathrm{CH}_{2} \mathrm{OH}\right)$ were purchased from Tianjin Chemical Reagents, China.

\subsection{Synthesis of the catalysts}

2.2.1 Synthesis of acid-treated VXC-72. For the preparation of acid treated VXC-72, $6.0 \mathrm{~g}$ of VXC-72 was mixed with $200 \mathrm{~mL}$ of $65 \% \mathrm{HNO}_{3}$, and the solution was sonicated for $10 \mathrm{~min}$ at 298 $\mathrm{K}$ and then stirred for $5 \mathrm{~h}$ at $348 \mathrm{~K}$ in an oil bath. After cooling down to room temperature, the mixture was slowly dropped into plenty of water in an ice-bath and collected by filtration and washed with distilled water until the $\mathrm{pH}$ was adjusted to 7 . The product was dried at $80^{\circ} \mathrm{C}$ overnight.

2.2.2 Synthesis of PdAu/VXC-72- $\mathrm{NH}_{2}$. Typically, $0.168 \mathrm{~g}$ of acid-treated VXC-72 was dispersed in a mixed solution of $35 \mathrm{~mL}$ $\mathrm{H}_{2} \mathrm{O}$ and $5 \mathrm{~mL}$ ethanol under ultrasonication for $30 \mathrm{~min}$. Subsequently, $0.6 \mathrm{~mL}$ of APTES was dispersed in $5 \mathrm{~mL}$ of ethanol and then added dropwise to the resulting black suspension. After ultrasonication at room temperature for 10 min, $5 \mathrm{~mL}$ aqueous solution containing $0.018 \mathrm{mmol} \mathrm{Na}_{2} \mathrm{PdCl}_{4}$ and $0.012 \mathrm{mmol} \mathrm{H}_{2} \mathrm{AuCl}_{4}$ was added to the dispersion with vigorous stirring for $1 \mathrm{~h}$ at $-3{ }^{\circ} \mathrm{C}$ (the temperature was controlled and maintained through circulating a cold pump).
Then, the fresh $\mathrm{NaBH}_{4}$ solution ( $100 \mathrm{mg} \mathrm{NaBH} 4$ dissolved in 10 $\mathrm{mL}_{2} \mathrm{O}$ ) was added to this mixture with continuous stirring for $5 \mathrm{~h}$ at $-3{ }^{\circ} \mathrm{C}$. The resultant black $\mathrm{Pd}_{0.6} \mathrm{Au}_{0.4} / \mathrm{VXC}-72-\mathrm{NH}_{2}$ product was separated by centrifugation and dried under vacuum at 25 ${ }^{\circ} \mathrm{C}$ for $24 \mathrm{~h}$. Moreover, the molar ratio of $\mathrm{Au}: \mathrm{Pd}$ in the PdAu/ VXC-72- $\mathrm{NH}_{2}$ system was changed $(0: 1,0.2: 0.8,0.6: 0.4$, $0.8: 0.2$, and $1: 0$ ). For comparison, $\mathrm{Pd}_{0.6} \mathrm{Au}_{0.4} / \mathrm{VXC}-72$ was prepared using a similar method without the addition of APTES.

\subsection{Characterization}

Transmission electron microscopy (TEM) was performed on a JEM-2800 microscope with an energy dispersive X-ray spectroscopy (EDX) detector, working at $200 \mathrm{kV}$ to analyze the surface morphology of the prepared samples. All the samples subjected to TEM measurements were ultrasonically dispersed in ethanol and dropped onto carbon films. Powder X-ray diffraction (XRD) patterns were recorded on a Rigaku Smart Lab $3000 \mathrm{~W}$ powder diffractometer using $\mathrm{Cu} \mathrm{K} \alpha$ radiation $(\lambda=$ $1.5418 \AA$ ). X-ray photoelectron spectroscopy (XPS) measurements were performed on a Thermofisher ESCALAB 250Xi spectrometer. The Raman spectra were obtained using a Raman spectrometer (SR-500I-A) using laser excitation at $532 \mathrm{~nm}$. Nitrogen adsorption and desorption isotherms were measured on a BELSORP-mini II sorption analyzer at $77 \mathrm{~K}$. The specific surface area was calculated by the BET (Brunauer-EmmettTeller) method, the pore-size distribution was calculated from the adsorption branch using the BJH (Barett-Joyner-Halenda) method and the total pore volume was obtained at a $P / P_{0}$ of 0.99 . The contents of Pd and Au were determined by inductively coupled plasma-atomic emission spectrometry (ICP-AES) on a Thermo Jarrell-Ash ICP-9000. The contact angle was measured on a JC2000D3M contact angle tester.

\subsection{FA dehydrogenation experiments}

The hydrogen production from FA solution was carried out in a $25 \mathrm{~mL}$ flask. Typically, $0.1 \mathrm{~g}$ of the $\mathrm{Pd}_{0.6} \mathrm{Au}_{0.4} / \mathrm{VXC}-72-\mathrm{NH}_{2}$ catalyst was kept in the flask, and then $5 \mathrm{~mL}$ of aqueous solution containing FA $(1 \mathrm{M})$ was injected quickly. The catalytic reaction begun after the FA solution was added to the flask under continuous magnetic stirring $(600 \mathrm{rpm})$ at $25^{\circ} \mathrm{C}$. The evolution of gas was monitored by using a gas burette. Concentrations of $\mathrm{H}_{2}, \mathrm{CO}_{2}$ and $\mathrm{CO}$ were measured on a GC (SP2100A) with a thermal conductivity detector (TCD) and a flame ionization detector (FID)-methanator and the detection limit for CO was $10 \mathrm{ppm}$.

\subsection{Durability testing of the catalysts}

For testing the durability of the as-prepared $\mathrm{Pd}_{0.6} \mathrm{Au}_{0.4} / \mathrm{VXC}-72-$ $\mathrm{NH}_{2}$ catalyst, $0.2 \mathrm{~mL}$ of pure $\mathrm{FA}$ was added to the reaction mixture after the complete conversion of the first-run composition of FA. Such recycle experiments for the synthesized catalyst for the decomposition of FA were carried out for 5 runs at $298 \mathrm{~K}$ by adding equivalent $\mathrm{FA}(5 \mathrm{mmol})$. After the durability testing, the catalyst was collected for XRD, XPS and TEM analyses. 


\subsection{Calculation methods}

The TOF value is based on the number of $\mathrm{Au}$ and $\mathrm{Pd}$ atoms in the catalyst, which is calculated from the initial TOF value, which is calculated when the conversion reaches $20 \%$. The equation is as follows:

$$
\mathrm{TOF}_{\text {initial }}=\frac{P_{\mathrm{atm}} V_{\mathrm{gas}} / R T}{2 n_{\mathrm{Au}+\mathrm{Pd}} t}
$$

where $P_{\text {atm }}$ is atmospheric pressure, $V_{\text {gas }}$ is the total generated volume of $\mathrm{H}_{2}-\mathrm{CO}_{2}$ gas at the time when the conversion reaches $20 \%, R$ is the universal gas constant, $T$ is room temperature (298 $\mathrm{K}), n_{\mathrm{Pd}+\mathrm{Au}}$ is the total mole number of $\mathrm{Pd}$ and $\mathrm{Au}$ atoms in the catalyst, and $t$ is the time when the conversion reaches $20 \%$.

\section{Results and discussion}

The design and fabrication procedure of $\mathrm{Pd}_{0.6} \mathrm{Au}_{0.4} / \mathrm{VXC}-72-\mathrm{NH}_{2}$ are summarized in Scheme 1. VXC-72 was first treated with highly concentrated nitric acid to generate grafting oxygencontaining functional groups $(-\mathrm{COOH}$ and $-\mathrm{OH})$. According to the literature, ${ }^{26,38}$ 3-aminopropyl-triethoxysilane (APTES) underwent hydrolysis in a water/ethanol mixture and the ethoxy groups were replaced by silanol groups, which would further react with the hydroxyl or carboxyl groups on the carbon black surface. Aqueous solutions of $\mathrm{H}_{2} \mathrm{AuCl}_{4}$ and $\mathrm{Na}_{2} \mathrm{PdCl}_{4}$ (with a $\mathrm{Au}$ : Pd molar ratio of $0.4: 0.6$ ) were added to the above APTES-treated VXC-72 solution and reduced with $\mathrm{NaBH}_{4}$ at -3 ${ }^{\circ} \mathrm{C}$ for $5 \mathrm{~h}$. The product $\mathrm{Pd}_{0.6} \mathrm{Au}_{0.4} / \mathrm{VXC}-72-\mathrm{NH}_{2}$ was obtained and used for catalytic $\mathrm{H}_{2}$ generation from FA solution.

The transmission electron microscopy (TEM) images of $\mathrm{Pd}_{0.6} \mathrm{Au}_{0.4} / \mathrm{VXC}-72-\mathrm{NH}_{2}$ showed that PdAu NPs with an average particle size of $1.5 \mathrm{~nm}$ were homogenously dispersed on VXC72- $\mathrm{NH}_{2}$ (Fig. 1a-c). In contrast, larger PdAu NPs with a mean size of $3.0 \mathrm{~nm}$ were observed for $\mathrm{Pd}_{0.6} \mathrm{Au}_{0.4} / \mathrm{VXC}-72$ (Fig. 1d-f). In addition, VXC-72 is hard to disperse in water uniformly due to its hydrophobicity (the water contact angle is shown in Fig. 2a), while VXC-72- $\mathrm{NH}_{2}$ functionalized with amine groups exhibited excellent hydrophilicity. As shown in Fig. 2b, VXC-72- $\mathrm{NH}_{2}$ could be uniformly dispersed in aqueous solution, and the catalyst
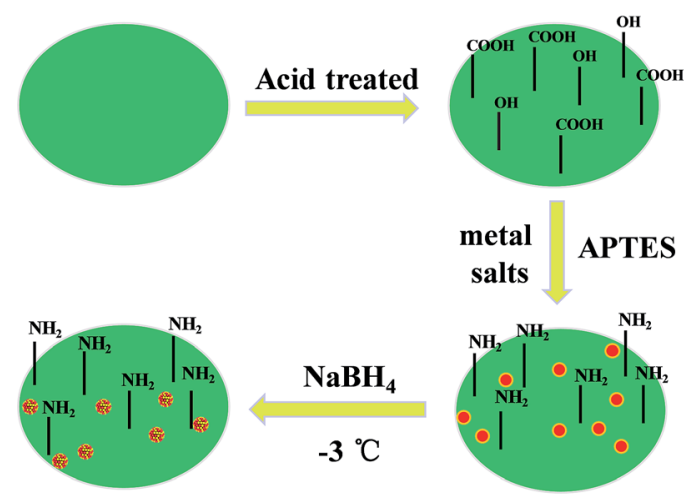

$\mathbf{P d}_{0.6} \mathbf{A u}_{0.4} / \mathrm{VXC}-72-\mathrm{NH}_{2}$

Scheme 1 Schematic illustration of the preparation of $\mathrm{Pd}_{0.6} \mathrm{Au}_{0.4} /$ VXC-72- $\mathrm{NH}_{2}$.
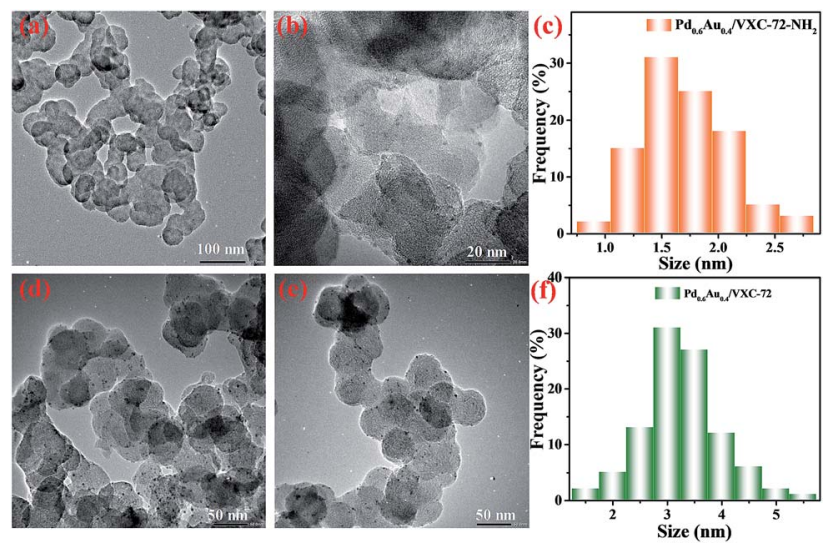

Fig. 1 TEM images and size distributions of $\mathrm{Pd}_{0.6} \mathrm{Au}_{0.4} / \mathrm{VXC}-72-\mathrm{NH}_{2}$ $(\mathrm{a}-\mathrm{c})$ and $\mathrm{Pd}_{0.6} \mathrm{Au}_{0.4} / \mathrm{VXC}-72(\mathrm{~d}-\mathrm{f})$.

suspension remained stable even after $24 \mathrm{~h}$. The hydrophilicity differences highlight the importance of amine functionalized VXC-72 as a support for mediating the ultrafine size and excellent dispersion of PdAu NPs. The energy-dispersive X-ray spectroscopy (EDX) result confirmed the existence of $\mathrm{N}, \mathrm{Au}$ and $\mathrm{Pd}$ in $\mathrm{Pd}_{0.6} \mathrm{Au}_{0.4} / \mathrm{VXC}-72-\mathrm{NH}_{2}$ (Fig. S1 $\dagger$ ). The accurate content of $\mathrm{Au}: \mathrm{Pd}$ in $\mathrm{Pd}_{0.6} \mathrm{Au}_{0.4} / \mathrm{VXC}-72-\mathrm{NH}_{2}$ was determined to be $0.42: 0.58$ by ICP-AES.

Brunauer-Emmett-Teller (BET) surface areas were calculated from the $\mathrm{N}_{2}$ adsorption desorption isotherms of the samples (Fig. S2†). The detailed textural parameters are summarized in Table S1. $\dagger$ It can be seen that compared with VXC-72 $\left(S_{\mathrm{BET}}=120 \mathrm{~m}^{2} \mathrm{~g}^{-1}\right)$, the surface area of amine functionalized carbon black was slightly reduced $\left(S_{\mathrm{BET}}=103 \mathrm{~m}^{2}\right.$ $\left.\mathrm{g}^{-1}\right)$. No obvious change was observed after the deposition of Pd and $\mathrm{Au}$ onto VXC-72- $\mathrm{NH}_{2}\left(S_{\mathrm{BET}}=108 \mathrm{~m}^{2} \mathrm{~g}^{-1}\right)$.

The XRD patterns of the as-prepared catalysts are shown in Fig. 3a. Two broad peaks at around $24.9^{\circ}$ and $43.3^{\circ}$ were ascribed to the (002) and (200) diffractions of amorphous carbon, respectively. ${ }^{39,40}$ For the sample $\mathrm{Pd}_{0.6} \mathrm{Au}_{0.4} / \mathrm{VXC}-72$, the diffraction peak at $38.7^{\circ}$ was just between the standard (111) planes of cubic Au (JCPDS: 65-2870) and cubic Pd (JCPDS: 652867), indicating the formation of a PdAu alloy structure. ${ }^{41-43}$ For the sample $\mathrm{Au} / \mathrm{VXC}-72-\mathrm{NH}_{2}$ the diffraction peaks at $38.2^{\circ}$ could be assigned to the (111) plane of metallic $\mathrm{Au}$ (JCPDS: 652870). However, $\mathrm{Pd} / \mathrm{VXC}-72-\mathrm{NH}_{2}$ and $\mathrm{Pd}_{0.6} \mathrm{Au}_{0.4} / \mathrm{VXC}-72-\mathrm{NH}_{2}$ showed no obvious diffraction peaks, indicating that ultra-

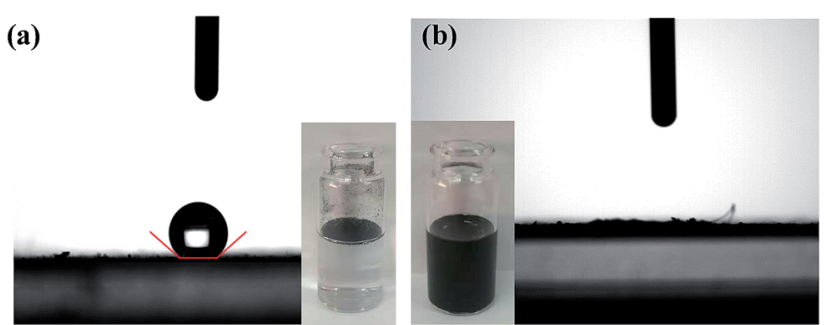

Fig. 2 Water-contact angle of (a) VXC-72 and (b) $V X C-72-\mathrm{NH}_{2}$ and the corresponding photos of $\mathrm{VXC}-72$ and $\mathrm{VXC}-72-\mathrm{NH}_{2}$ suspension. 

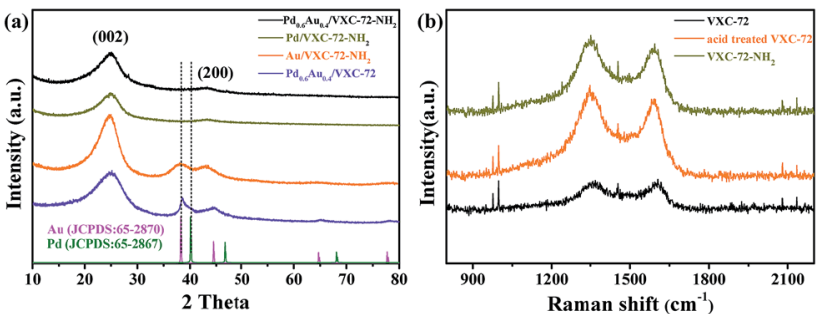

Fig. 3 (a) XRD patterns of the as-synthesized catalysts and (b) Raman spectra of the as synthesized VXC-72 supports.

small Pd and PdAu particles were well dispersed on the support. ${ }^{24}$ Therefore, the presence of amines was the key factor for the formation of the ultrasmall PdAu NPs. Moreover, after annealing of $\mathrm{Pd}_{0.6} \mathrm{Au}_{0.4} / \mathrm{VXC}-72-\mathrm{NH}_{2}$ in an $\mathrm{Ar}$ atmosphere (773 $\mathrm{K}, 3 \mathrm{~h}$ ), there appeared a diffraction peak at about $38.7^{\circ}$, confirming that the PdAu NPs were in an alloy structure (Fig. S3†). ${ }^{42}$ In the Raman spectra (Fig. 3b) the wide bands at around 1344 and $1591 \mathrm{~cm}^{-1}$ were ascribed to the disordered graphite carbon (D-band) and $\mathrm{sp}^{2}$-carbon (G-band) within aromatic carbon rings, respectively. ${ }^{44}$ After acid treatment, the $\mathrm{D} / \mathrm{G}$ ratio increased, indicating a decrease of the $\mathrm{sp}^{2}$-hybridized structure that generates defects and edge planes. The D/G ratio of VXC-72$\mathrm{NH}_{2}$ remained almost the same as that of acid treated VXC-72, implying that amine functionalization induced no damage to the structure of the carbon matrix.

X-ray photoelectron spectroscopy (XPS) investigation confirmed the existence of abundant $\mathrm{O}$ and $\mathrm{N}$ species after amine functionalization of VXC-72 (Fig. 4 and Table S2 $\dagger$ ). The binding energy of $\mathrm{Au}$ and $\mathrm{Pd}$ in $\mathrm{Pd}_{0.6} \mathrm{Au}_{0.4} / \mathrm{VXC}-72-\mathrm{NH}_{2}$ indicated the valence of metallic $\mathrm{Au}^{0}$ and $\mathrm{Pd}^{0}$ (Fig. 5). ${ }^{45}$ Additionally, the XPS results showed that the binding energy of Pd $3 \mathrm{~d}$ in $\mathrm{Pd}_{0.6} \mathrm{Au}_{0.4} / \mathrm{VXC}-72-\mathrm{NH}_{2}$ was shifted to a higher value relative to that in $\mathrm{Pd} / \mathrm{VXC}-72-\mathrm{NH}_{2}$, while binding energies of $\mathrm{Au} 4 \mathrm{f}$ in $\mathrm{Pd}_{0.6} \mathrm{Au}_{0.4} / \mathrm{VXC}-72-\mathrm{NH}_{2}$ were shifted to the lower value compared with that in $\mathrm{Au} / \mathrm{VXC}-72-\mathrm{NH}_{2}$. These shifts could be attributed to a partial electron-transfer from $\mathrm{Pd}$ to $\mathrm{Au}$, which could be explained by the lower electronegativity of Pd than $\mathrm{Au}$
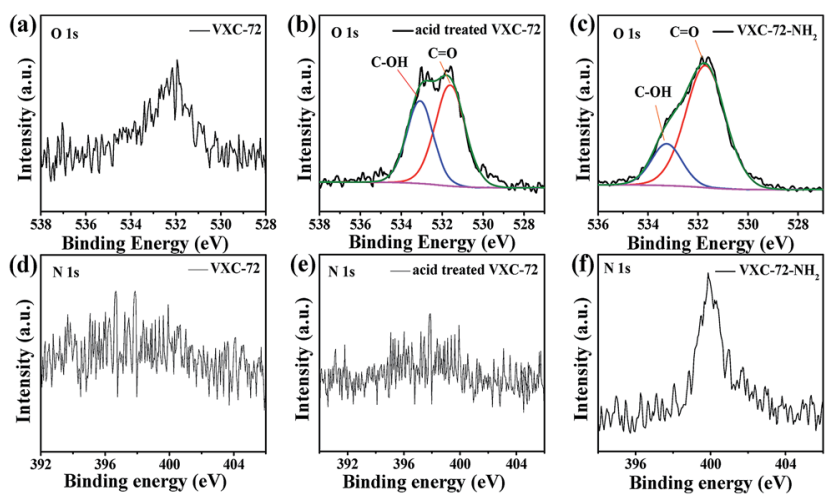

Fig. 4 XPS spectra of $O 1$ s for (a) VXC-72, (b) acid treated VXC-72 and (c) VXC-72- $\mathrm{NH}_{2}$ and $\mathrm{N}$ 1s for (d) VXC-72 (e) acid treated VXC-72 and (f) VXC-72- $\mathrm{NH}_{2}$.
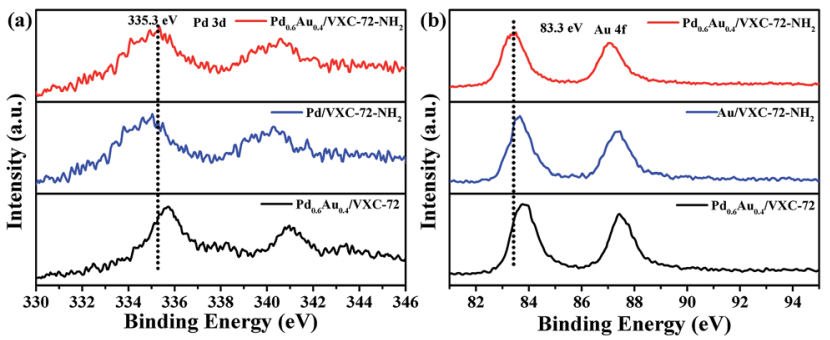

Fig. 5 XPS spectra of (a) Pd $3 d$ and (b) $\mathrm{Au} 4 \mathrm{f}$ in $\mathrm{Pd}_{0.6} \mathrm{Au}_{0.4} / \mathrm{VXC}-72-$ $\mathrm{NH}_{2}, \mathrm{Pd}_{0.6} \mathrm{Au}_{0.4} / \mathrm{VXC}-72, \mathrm{Pd} / \mathrm{VXC}-72-\mathrm{NH}_{2}$ and $\mathrm{Au} / \mathrm{VXC}-72-\mathrm{NH}_{2}$.

(Pd 2.2, Au 2.4) due to the alloy effect between Pd and Au. Moreover, the Pd $3 \mathrm{~d}$ and $\mathrm{Au} 4 \mathrm{f}$ peaks of $\mathrm{Pd}_{0.6} \mathrm{Au}_{0.4} / \mathrm{VXC}-72-\mathrm{NH}_{2}$ were both shifted to lower binding energies in comparison to those of $\mathrm{Pd}$ and $\mathrm{Au}$ on $\mathrm{Pd}_{0.6} \mathrm{Au}_{0.4} / \mathrm{VXC}-72$, and the shifts indicated that some electrons were transferred from the VXC-72$\mathrm{NH}_{2}$ substrate to the PdAu NPs, confirming the strong interaction between the VXC-72- $\mathrm{NH}_{2}$ support and PdAu NPs. ${ }^{41}$

Fig. 6 shows the catalytic activity of the as-prepared catalysts for the dehydrogenation of FA at $298 \mathrm{~K}$. It can be seen that without Pd addition, the $\mathrm{Au} / \mathrm{VXC}-72-\mathrm{NH}_{2}$ catalyst did not show any activity. The catalyst $\mathrm{Pd}_{0.6} \mathrm{Au}_{0.4} / \mathrm{VXC}^{-72-\mathrm{NH}_{2}}$ showed a high catalytic activity and $245 \mathrm{~mL}$ of gas was released within $8 \mathrm{~min}$ at $298 \mathrm{~K}$, affording a turnover frequency (TOF) value of $7385 \mathrm{~h}^{-1}$, the highest value at room temperature reported so far. In contrast, the catalyst $\mathrm{Pd}_{0.6} \mathrm{Au}_{0.4} / \mathrm{VXC}-72$ showed a much lower activity for the decomposition of FA under the same conditions,
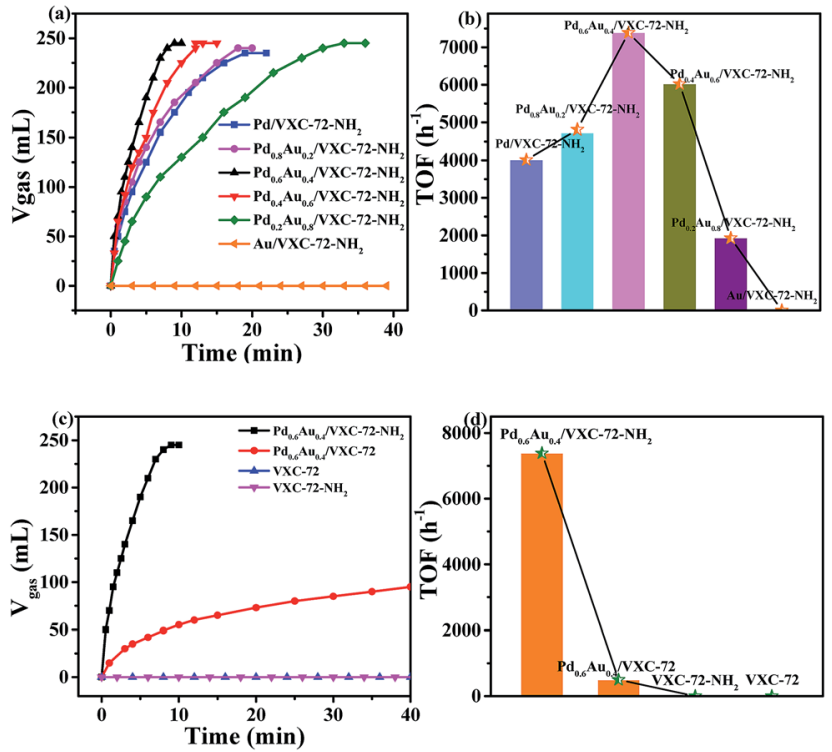

Fig. 6 (a) Volume of the generated gas $\left(\mathrm{CO}_{2}+\mathrm{H}_{2}\right)$ from the decomposition of FA $(1.0 \mathrm{M}, 5.0 \mathrm{~mL})$ versus time in the presence of $\mathrm{Pd}_{x} \mathrm{Au}_{1-x} / \mathrm{VXC}-72-\mathrm{NH}_{2}$ and (b) the corresponding TOF values; (c) volume of the generated gas $\left(\mathrm{CO}_{2}+\mathrm{H}_{2}\right)$ from the decomposition of FA versus time in the presence of $\mathrm{Pd}_{0.6} \mathrm{Au}_{0.4} / \mathrm{VXC}-72-\mathrm{NH}_{2}, \mathrm{Pd}_{0.6} \mathrm{Au}_{0.4} /$ $\mathrm{VXC}-72, \mathrm{VXC}-72-\mathrm{NH}_{2}$ and $\mathrm{VXC}-72$ at $298 \mathrm{~K}\left(\left(n_{\mathrm{Pd}+\mathrm{Au}} / n_{\mathrm{FA}}\right)=0.0034\right)$ and (d) the corresponding TOF values. The TOF value was calculated at a conversion of $20 \%$. 
over which only $73 \mathrm{~mL}$ of gas was released in $20 \mathrm{~min}$ (Fig. 6c). The calculated TOF value of $\mathrm{Pd}_{0.6} \mathrm{Au}_{0.4} / \mathrm{VXC}-72-\mathrm{NH}_{2}\left(7385 \mathrm{~h}^{-1}\right)$ was greater than that on the $\mathrm{Pd}_{0.6} \mathrm{Au}_{0.4} / \mathrm{VXC}-72$ catalyst $\left(497 \mathrm{~h}^{-1}\right)$ by a factor of 15 .

Obviously, the significant enhancement of the catalytic performance of $\mathrm{Pd}_{0.6} \mathrm{Au}_{0.4} / \mathrm{VXC}-72-\mathrm{NH}_{2}$ could be ascribed to the hydrophilic VXC-72- $\mathrm{NH}_{2}$ support for the synthesis of ultrafine PdAu NPs. The catalytic activity is much higher than that of Pd or Pd-based alloy supported by amine functionalized rGO, ${ }^{21,24,26,27,37}$ mesoporous carbon, ${ }^{25}$ MOFs, ${ }^{29,35}$ and mesoporous silica, ${ }^{32-34,36}$ as listed in Table 1 . As reported in the literature ${ }^{15}$ for supported noble metal catalysts, the interaction between the metal and support is closely related to the catalytic activity. The functionalization of carbon black by amine converted the hydrophobic surface to a hydrophilic surface, which was beneficial to the formation of highly dispersed ultrafine PdAu NPs. Meanwhile the presence of amine groups modulated the electronic structure of PdAu NPs, and all these factors lead to greatly improved activity.

The gas mixture generated from FA catalyzed by $\mathrm{Pd}_{0.6} \mathrm{Au}_{0.4} /$ VXC-72- $\mathrm{NH}_{2}$ was analyzed by gas chromatography (GC) to be $\mathrm{CO}_{2}$ and $\mathrm{H}_{2}$, and no $\mathrm{CO}$ could be detected from the evolved gas (Fig. 7), suggesting that the as-prepared $\mathrm{Pd}_{0.6} \mathrm{Au}_{0.4} / \mathrm{VXC}-72-\mathrm{NH}_{2}$ has a $100 \%$ selectivity to $\mathrm{H}_{2}$ from FA. Gas generation over $\mathrm{Pd}_{0.6} \mathrm{Au}_{0.4} / \mathrm{VXC}-72-\mathrm{NH}_{2}$ was completed in 9, 8, 7.5, 7 and $5.5 \mathrm{~min}$ at $298,303,313,323$ and $333 \mathrm{~K}$, respectively (Fig. 8), corresponding to TOF values of 7385, 8491, 11037,14179 and 17724 $\mathrm{h}^{-1}$. The apparent activation energy $\left(E_{\mathrm{a}}\right)$ was determined to be $20.6 \mathrm{~kJ} \mathrm{~mol}^{-1}$, which was lower than most of the reported values (Table 1).

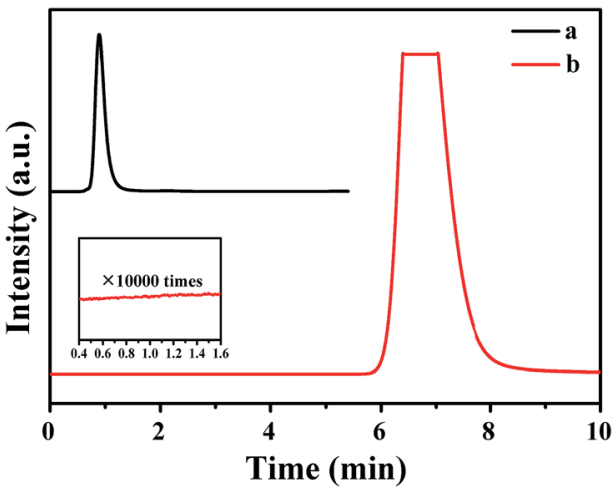

Fig. 7 GC spectra collected using a FID-methanator for the (a) mixed gas of $\mathrm{CO} / \mathrm{Ar}$ and (b) evolved gas from $\mathrm{FA}$ aqueous solution (1.0 M, 5.0 $\mathrm{mL})$ over the $\mathrm{Pd}_{0.6} \mathrm{Au}_{0.4} / \mathrm{VXC}-72-\mathrm{NH}_{2}$ catalyst at $298 \mathrm{~K}\left(\left(n_{\mathrm{Pd}+\mathrm{Au}} / n_{\mathrm{FA}}\right)=\right.$ 0.0034).

The recycling stability of $\mathrm{Pd}_{0.6} \mathrm{Au}_{0.4} / \mathrm{VXC}-72-\mathrm{NH}_{2}$ was also evaluated by further addition of an equivalent of FA to the reaction mixture after the completion of the previous cycle. As shown in Fig. 9, there was no significant decrease in catalytic activity after the fifth run. In addition, the results of XRD (Fig. S4 $\dagger$ ) and TEM images (Fig. S5 $\dagger$ ) of $\mathrm{Pd}_{0.6} \mathrm{Au}_{0.4} / \mathrm{VXC}-72-\mathrm{NH}_{2}$ after the fifth run showed no obvious change in the PdAu alloy size. The XPS result showed that after recycled use, the elements N, Au and Pd were stable on carbon black (Fig. S6 $\dagger$ ), and the atomic percentage is listed in Table S2. $\uparrow$ The contents of $\mathrm{Au}$ and Pd in the samples determined by ICP-AES are listed in Table $\mathrm{S} 3, \dagger$ and the results showed that there was no obvious loss of $\mathrm{N}, \mathrm{Au}$ and $\mathrm{Pd}$ in recycled $\mathrm{Pd}_{0.6} \mathrm{Au}_{0.4} / \mathrm{VXC}-72$ -

Table 1 Catalytic activities for the dehydrogenation of formic acid catalyzed by various heterogeneous catalysts

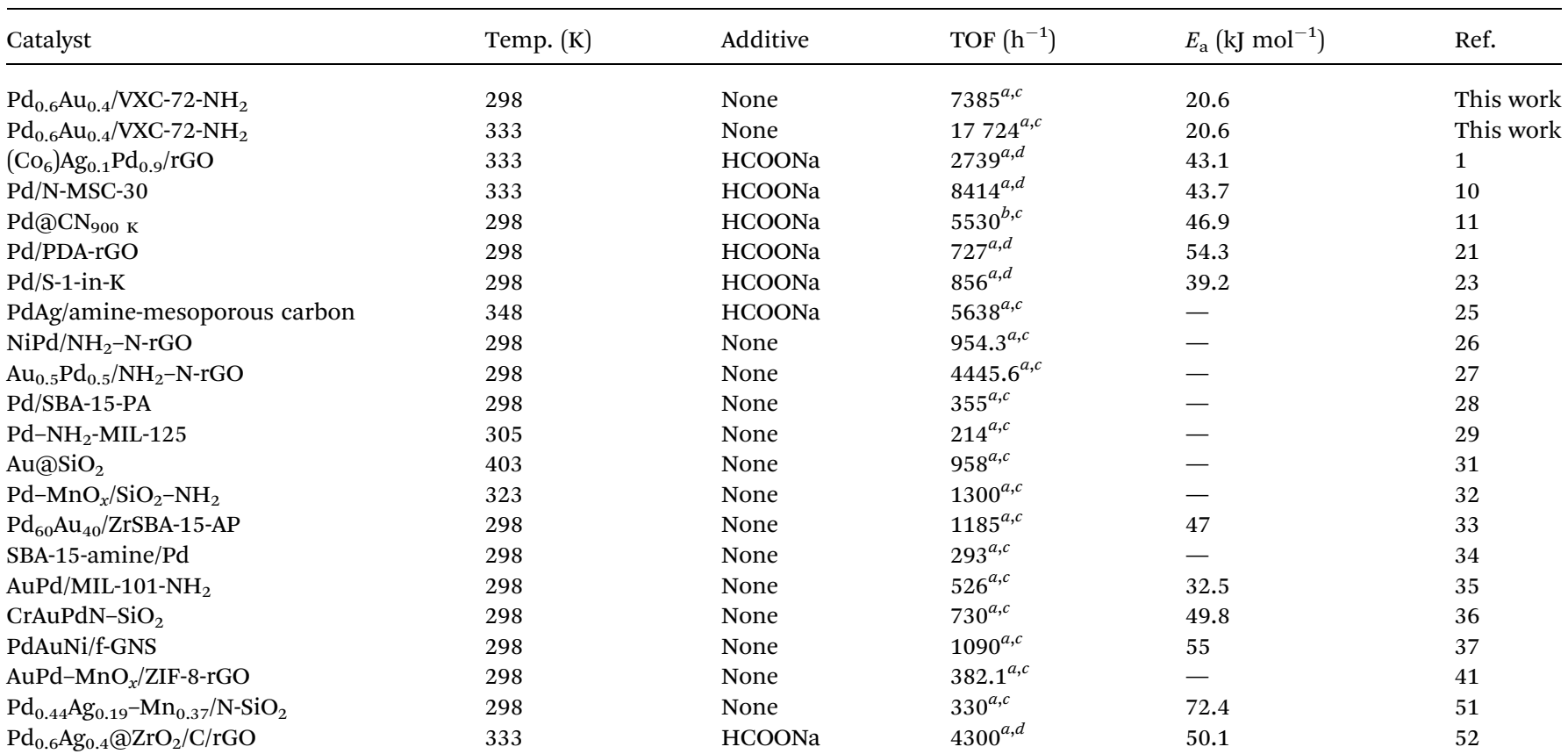

${ }^{a}$ TOF values calculated for total metal atoms. ${ }^{b}$ TOF values calculated on surface metal sites or active sites. ${ }^{c}$ Initial TOF values calculated at the initial time or initial conversion of FA. ${ }^{d}$ TOF values calculated at the complete time of gas release. 

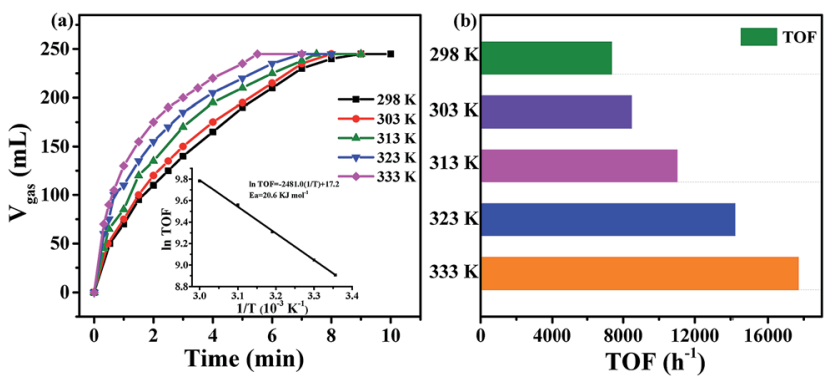

Fig. 8 (a) Volume of generated gas $\left(\mathrm{CO}_{2}+\mathrm{H}_{2}\right)$ versus the reaction time at $298 \mathrm{~K}\left(\left(n_{\mathrm{Pd}+\mathrm{Au}} / n_{\mathrm{FA}}\right)=0.0034\right)$ and (b) TOF values of $\mathrm{H}_{2}$ generation for the dehydrogenation of $F A$ over the $\mathrm{Pd}_{0.6} \mathrm{Au}_{0.4} / \mathrm{VXC}-72-\mathrm{NH}_{2}$ catalyst at different reaction temperatures. Inset in (a): Arrhenius plot (In (TOF) vs. $1 / T)$.

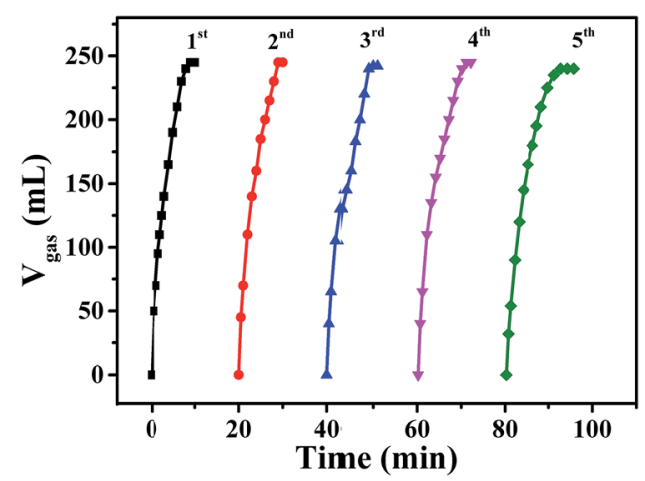

Fig. 9 Durability test for the dehydrogenation of FA solution over $\mathrm{Pd}_{0.6} \mathrm{Au}_{0.4} / \mathrm{VXC}-72-\mathrm{NH}_{2}$ at $298 \mathrm{~K}$.

$\mathrm{NH}_{2}$, indicating good catalytic durability and stability of the catalyst.

The results above suggested that VXC-72- $\mathrm{NH}_{2}$ could efficiently anchor the PdAu NPs, preventing aggregation and overgrowth during the synthetic and catalytic processes. The amine groups on the support could serve the following roles.

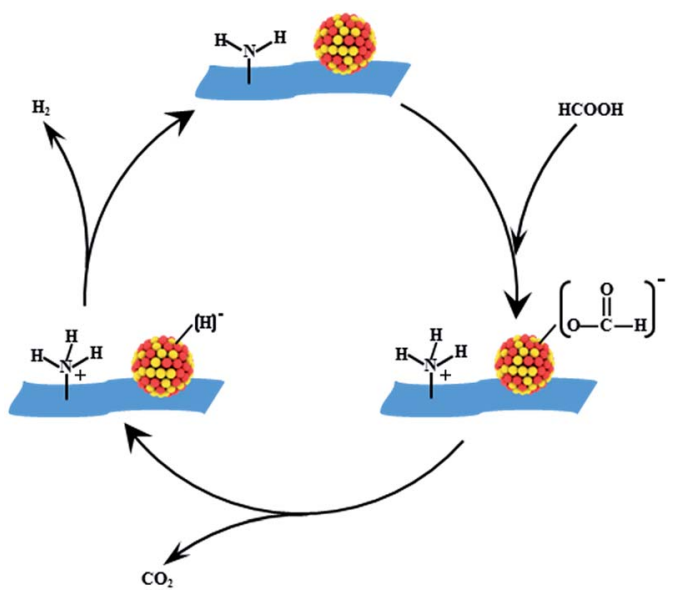

Scheme 2 Possible reaction pathway of FA decomposition over $\mathrm{Pd}_{0.6} \mathrm{Au}_{0.4} / \mathrm{VXC}-72-\mathrm{NH}_{2}$.
First, $-\mathrm{NH}_{2}$ would convert the surface of carbon black to be hydrophilic and give rise to ultrafine sizes and excellent dispersion of nanoparticles. Second, the alkaline $-\mathrm{NH}_{2}$ group could facilitate $\mathrm{O}-\mathrm{H}$ bond dissociation of $\mathrm{FA}$ to produce $-\left[\mathrm{H}_{2} \mathrm{NH}\right]^{+}$and metal-formate species. Moreover, the electron modification of VXC-72- $\mathrm{NH}_{2}$ toward PdAu NPs would increase the electron density of PdAu active centers to facilitate the formation of metal-formate, which enhanced the rate of the catalytic dehydrogenation of FA. ${ }^{46-48}$ As illustrated in Scheme 2, the alkaline $-\mathrm{NH}_{2}$ group could serve as a proton scavenger, which benefits the $\mathrm{O}-\mathrm{H}$ bond dissociation in the FA molecule, resulting in the formation of a metal-formate intermediate along with the $\left[\mathrm{H}_{2} \mathrm{NH}\right]^{+}$group during the initial step of the reaction. Subsequently, the PdAu-formate species undergo $\beta$ hydride elimination to produce $\mathrm{CO}_{2}$ and a palladium hydride species. Finally, $\mathrm{H}_{2}$ is produced from the palladium hydride species and $[\mathrm{H}]^{+} . \mathrm{H}^{21,49,50}$

\section{Conclusions}

In summary, ultrafine and highly dispersed PdAu NPs were immobilized on amine functionalized carbon black, and the catalyst $\mathrm{Pd}_{0.6} \mathrm{Au}_{0.4} / \mathrm{VXC}-72-\mathrm{NH}_{2}$ exhibited excellent activity for FA dehydrogenation without any additives at room temperature. The functionalization of carbon black with amines converted the hydrophobic surface to a hydrophilic surface, which was beneficial to the formation of highly dispersed ultrafine PdAu NPs. Meanwhile the presence of amine groups could modulate the electronic structure of PdAu NPs, leading to greatly improved activity. As carbon supports (activated carbon and carbon black) are widely used for industrial supported noble metal catalysts, our study provides a general approach for the design of ultrafine and highly dispersed noble metal catalysts, not only for enhanced dehydrogenation of FA but also for more efficient industrial applications with carbon supported noble metal catalysts.

\section{Conflicts of interest}

The authors declare no competing financial interests.

\section{Acknowledgements}

This work was supported by the NSFC (No. 21773128, 21534005, and 21421001).

\section{References}

1 Y. Chen, Q. L. Zhu, N. Tsumori and Q. Xu, J. Am. Chem. Soc., 2015, 137, 106-109.

2 B. Liu, H. Yao, W. Song, L. Jin, I. M. Mosa, J. F. Rusling, S. L. Suib and J. He, J. Am. Chem. Soc., 2016, 138, 4718-4721.

3 Q. L. Zhu and Q. Xu, Chem, 2016, 1, 220-245.

4 Q. Wang, N. Tsumori, M. Kitta and Q. Xu, ACS Catal., 2018, 8, 12041-12045.

5 B. Wu, Y. Kuang, X. Zhang and J. Chen, Nano Today, 2011, 6, 75-90. 
6 Q. L. Zhu, D. C. Zhong, U. B. Demirci and Q. Xu, ACS Catal., 2014, 4, 4261-4268.

7 S. H. Ye, F. Y. Luo, Q. L. Zhang, P. Y. Zhang, T. T. Xu, Q. D. Wang, S. He, L. C. Guo, Y. Zhang, C. X. He, X. P. Ouyang, M. Gu, J. H. Liu and X. L. Sun, Energy Environ. Sci., 2019, 12, 1000.

8 S. J. Jiang, Y. W. Ma, G. Q. Jian, H. S. Tao, X. Z. Wang, Y. N. Fan, Y. N. Lu, Z. Hu and Y. Chen, Adv. Mater., 2009, 21, 4953.

9 Z. Li, J. Liu, C. Xia and F. Li, ACS Catal., 2013, 3, 2440-2448.

10 Z. Li, X. Yang, N. Tsumori, Z. Liu, Y. Himeda, T. Autrey and Q. Xu, ACS Catal., 2017, 7, 2720-2724.

11 Q. Y. Bi, J. D. Lin, Y. M. Liu, H. Y. He, F. Q. Huang and Y. Cao, Angew. Chem., 2016, 55, 11849-11853.

12 J. Sun, H. Qiu, W. Cao, H. Fu, H. Wan, Z. Xu and S. Zheng, ACS Sustainable Chem. Eng., 2018, 7, 1963-1972.

13 K. J. Jeon, H. R. Moon, A. M. Ruminski, B. Jiang, C. Kisielowski, R. Bardhan and J. J. Urban, Nat. Mater., 2011, 10, 286-290.

14 J. Eppinger and K. W. Huang, ACS Energy Lett., 2017, 2, 188195.

15 H. Zhong, M. Iguchi, M. Chatterjee, Y. Himeda, Q. Xu and H. Kawanami, Adv. Sustainable Syst., 2018, 2, 1700161.

16 X. C. Yang, P. Pachfule, Y. Chen, N. Tsumoric and Q. Xu, Chem. Commun., 2016, 52, 4171.

17 Z. P. Li and Q. Xu, Acc. Chem. Res., 2017, 50, 1449-1458.

18 Z. P. Li and Q. Xu, Nanoscale, 2015, 7, 8321.

19 J. Cheng, X. J. Gu, X. Sheng, P. L. Liu and H. Q. Su, J. Mater. Chem. A, 2016, 4, 1887.

20 K. Jiang, K. Xu, S. Zou and W. B. Cai, J. Am. Chem. Soc., 2014, 136, 4861-4864.

21 F. Z. Song, Q. L. Zhu, N. Tsumori and Q. Xu, ACS Catal., 2015, 5, 5141-5144.

22 D. A. Bulushev, M. Zacharska, E. V. Shlyakhova, A. L. Chuvilin, Y. Guo, S. Beloshapkin, A. V. Okotrub and L. G. Bulusheva, ACS Catal., 2015, 6, 681-691.

23 N. Wang, Q. Sun, R. Bai, X. Li, G. Guo and J. Yu, J. Am. Chem. Soc., 2016, 138, 7484-7487.

24 H. Zhong, M. Iguchi, M. Chatter-jee, T. Ishizaka, M. Kitta, M. Q. Xu and H. Kawanami, ACS Catal., 2018, 8, 5355-5362.

25 S. Masuda, K. Mori, Y. Futamura and H. Yamashita, ACS Catal., 2018, 8, 2277-2285.

26 J. M. Yan, S. J. Li, S. S. Yi, B. R. Wulan, W. T. Zheng and Q. Jiang, Adv. Mater., 2018, 30, 1703038.

27 S. J. Li, Y. T. Zhou, X. Kang, D. X. Liu, L. Gu, Q. H. Zhang, J. M. Yan and Q. Jiang, Adv. Mater., 2019, 31, 1806781.

28 K. Koh, M. Jeon, C. W. Yoon and T. Asefa, J. Mater. Chem. A, 2017, 5, 16150.

29 M. Martis, K. Mori, K. Fujiwara, W. S. Ahn and H. Yamashita, J. Phys. Chem. C, 2013, 117, 22805-22810.
30 M. Yadav, T. Akita, N. Tsumori and Q. Xu, J. Mater. Chem., 2012, 22, 12582-12586.

31 J. Mielby, A. J. Kunov-Kruse and S. Kegnæs, J. Catal., 2017, 345, 149-156.

32 A. Buluta, M. Yurderia, Y. Karatasa, M. Zahmakirana, H. Kivrakb, M. Gulcana and M. Kaya, Appl. Catal., B, 2015, 164, 324-333.

33 Z. Z. Wang, X. F. Hao, D. W. Hu, L. Li, X. J. Song, W. X. Zhang and M. J. Jia, Catal. Sci. Technol., 2017, 7, 2213.

34 K. Koh, J. E. Seo, J. H. Lee, A. Goswami, C. W. Yoo and T. Asefa, J. Mater. Chem. A, 2014, 2, 20444-20449.

35 J. Cheng, X. J. Gu, P. L. Liu, H. Zhang, L. L. Ma and H. Q. Su, Appl. Catal., B, 2017, 218, 460-469.

36 M. Yurderi, A. Bulut, N. Caner, M. Celebi, M. Kayab and M. Zahmakiran, Chem. Commun., 2015, 51, 11417-11420.

37 A. Bulut, M. Yurderi, M. Kaya, M. Aydemir, A. Baysal, F. Durapc and M. Zahmakiran, New J. Chem., 2018, 42, 16103.

38 K. Kim, H. Oh, J. Kim, S. Ha, M. Kim, J. L. Yang and J. Kim, J. Nanosci. Nanotechnol., 2019, 19, 1525-1532.

39 Z. L. Wang, J. M. Yan, Y. Ping, H. L. Wang, W. T. Zheng and Q. Jiang, Angew. Chem., 2013, 52, 4406-4409.

40 Q. L. Zhu, N. Tsumori and Q. Xu, J. Am. Chem. Soc., 2015, 137, 11743-11748.

41 J. M. Yan, Z. L. Wang, L. Gu, S. J. Li, H. L. Wang, W. T. Zheng and Q. Jiang, Adv. Energy Mater., 2015, 5, 1500107.

42 S. Wu, F. Yang, H. Wang, R. Chen, P. C. Sun and T. H. Chen, Chem. Commun., 2015, 51, 10887.

43 Z. L. Wang, J. M. Yan, Y. F. Zhang, Y. Ping, H. L. Wang and Q. Jiang, Nanoscale, 2014, 6, 3073.

44 K. A. Wepasnick, B. A. Smith, K. E. Schrote, H. K. Wilson, S. R. Diegelmann and D. H. Fairbrother, Carbon, 2011, 49, 24-36.

45 Z. L. Wang, H. L. Wang, J. M. Yan, Y. Ping, S. I. O, S. J. Li and Q. Jiang, Chem. Commun., 2014, 50, 2732-2734.

46 K. Tedsree, T. Li, S. Jones, C. W. A. Chan, K. M. K. Yu, P. A. J. Bagot, E. A. Marquis, G. D. W. Smith and S. C. E. Tsang, Nat. Nanotechnol., 2011, 6, 302.

47 S. Jones, J. Qu, K. Tedsree, X. Q. Gong and S. C. E. Tsang, Angew. Chem., Int. Ed., 2012, 51, 11275.

48 K. Tedsree, C. W. A. Chan, S. Jones, Q. Cuan, W. K. Li, X. Q. Gong and S. C. E. Tsang, Science, 2011, 332, 224.

49 K. Mori, M. Dojo and H. Yamashita, ACS Catal., 2013, 3, 1114-1119.

50 J. S. Yoo, F. Abild-Pedersen, J. K. Nørskov and F. Studt, ACS Catal., 2014, 4, 1226-1233.

51 A. Bulut, M. Yurderi, Y. Karatas, Z. Say, H. Kivrak, M. Kaya, M. Gulcan, E. Ozensoy and M. Zahmakiran, ACS Catal., 2015, 5, 6099-6110.

52 F. Z. Song, Q. L. Zhu, X. Yang, W. W. Zhan, P. Pachfule, N. Tsumori and Q. Xu, Adv. Energy Mater., 2018, 8, 1701416. 